\title{
WestVirginiaUniversity
}

THE RESEARCH REPOSITORY @ WVU

Graduate Theses, Dissertations, and Problem Reports

2018

\section{0 days in Appalachia: publication building toolkit}

Kassandra Taylor

Follow this and additional works at: https://researchrepository.wvu.edu/etd

\section{Recommended Citation}

Taylor, Kassandra, "100 days in Appalachia: publication building toolkit" (2018). Graduate Theses, Dissertations, and Problem Reports. 3993.

https://researchrepository.wvu.edu/etd/3993

This Problem/Project Report is protected by copyright and/or related rights. It has been brought to you by the The Research Repository @WVU with permission from the rights-holder(s). You are free to use this Problem/Project Report in any way that is permitted by the copyright and related rights legislation that applies to your use. For other uses you must obtain permission from the rights-holder(s) directly, unless additional rights are indicated by a Creative Commons license in the record and/ or on the work itself. This Problem/Project Report has been accepted for inclusion in WVU Graduate Theses, Dissertations, and Problem Reports collection by an authorized administrator of The Research Repository @ WVU. For more information, please contact researchrepository@mail.wvu.edu. 
100 DAYS IN APPALACHIA:

PUBLICATION BUILDING TOOLKIT

by

\author{
Kassandra Taylor \\ A project submitted to the Reed College of Media \\ at West Virginia University \\ in partial fulfillment of the requirements \\ for the degree of
}

Master of Science

In

Journalism

Approved by

Dana Coester, Committee Chairperson

Gina Dahlia

Tyler Channell

Frank Ahrens

Morgantown, West Virginia

2018

Keywords: Journalism

Copyright 2018 Kassandra Taylor 


\title{
Abstract \\ 100 DAYS IN APPALACHIA: PUBLICATION BUILDING TOOLKIT
}

\author{
Kassandra Taylor
}

This is an analysis of the multimedia news outlet 100 Days in Appalachia. It is an attempt to examine the publication in order to further understand the purpose, the successes and the contributions it has made to journalism. 100 Days in Appalachia is delivering groundbreaking journalism from the heart of the region Appalachia, to help change perceptions about a part of the country that is widely misunderstood. This analysis will use 100 Days in Appalachia as a guideline to develop a journalists' toolkit for other communities throughout the United States to create a publication. It will also use information and suggestions gathered through interviews with the publications leadership in development of said toolkit. 


\section{Table of Contents}

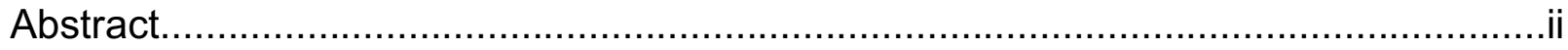

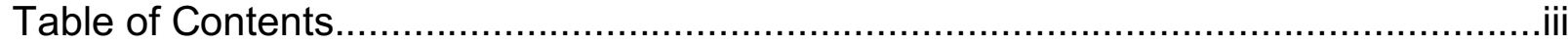

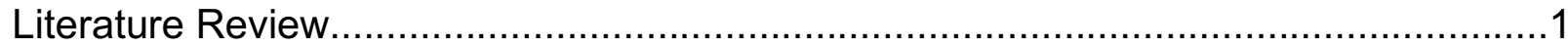

Media Coverage and perceptions of Appalachia.............................................

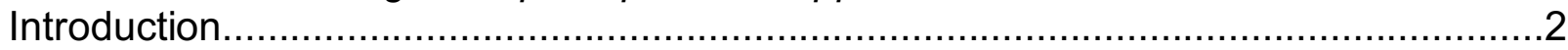

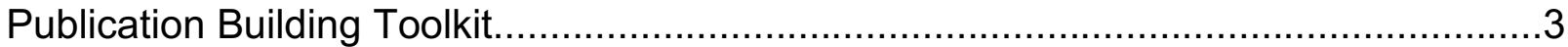

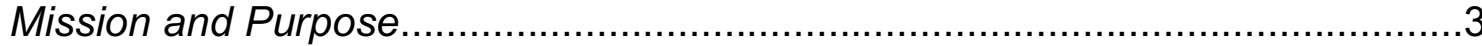

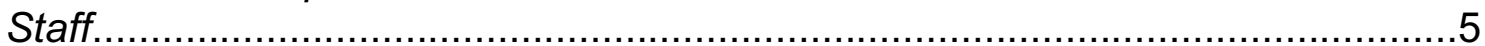

Is journalism without diversity really journalism?.................................

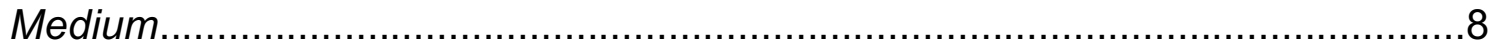

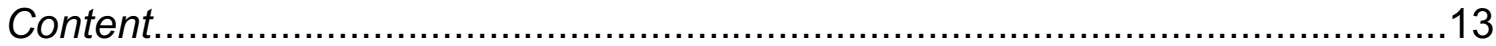

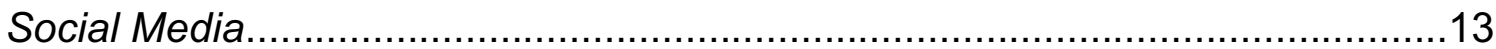

The downsides of social media......................................................15

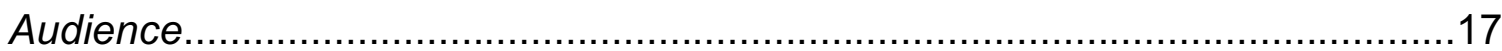

How to maintain audience relationships..........................................17

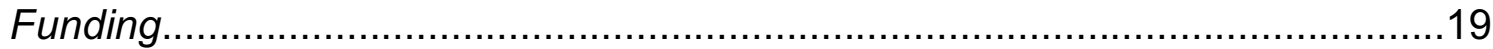

Methodology

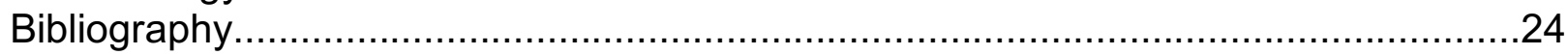





\section{Literature Review}

\section{Media Coverage and Perceptions of Appalachia}

West Virginia lies in the heart of Appalachia and is one of only 13 states that are a part of the region. Many would say West Virginians are a bit biased because of their strong ties to the area and often claim Appalachia as their own. But there is rich history and culture throughout the entire region that many don't know about. The 100 Days in Appalachia team saw that there was a huge identification gap not only from an outsider's perspective but from inside of the region as well. How many people in northern Pennsylvania or northern Alabama identify with Appalachia? It's easy to guess - not many - and given the stereotypes that surround West Virginia and its neighbors, not many people would want to. And this gives the "100 Days" team validation, all the more reason to bust stereotypes and give the region its voice back.

Linguistics Professor Kirk Hazen at West Virginia University studies negative perceptions of Appalachia and the driving force behind those views through the West Virginia Dialect Project. The project focuses on speech and dialect in Appalachia and how those relate to common perceptions of the area. Hazen says, "No other region gets more negative press and wildly inaccurate statements said about it than does Appalachia" and it's easy to agree with him (Shaffer, 2017).

Over the past decade Appalachia has reached national headlines only a handful of times, many of those stories originating in West Virginia:

- 2010 - Upper Big Branch mine disaster

- 2012 - Powerful storms leave 500K without power, Yeager Airport landslide in Charleston, WV

- 2014 - West Virginia chemical spill in the Elk River

- 2016 - 26 heroin/opioid overdoses in Huntington, WV in 4 hours

- 2018 - Teachers strike for pay and benefits, Senate at a standstill

Outside of the Mountain State, views of Appalachia are often skewed because of these big stories and dominating narratives of coal and opioids. There were nearly 43- 
thousand drug overdose deaths in the United States in 2016 and Appalachian states West Virginia, Ohio, Pennsylvania, and Kentucky were ranked among the top five states with highest rates of death due to drug overdose (Hedegaard, 2016). Particularly tragic headlines came out of West Virginia and Ohio over the past year and a half. In 2016, Huntington, WV reported 26 overdoses in four hours sparking even more conversation about the heroin and opioid problem in the state and region. In September 2016 a picture tweeted out by an East Liverpool, $\mathrm{OH}$ police officer went viral for showing two heroin users passed out in the front seat of their car while their child sat awake in a car seat in the back (Park, 2017). These aren't the only cases of opioid overdoses that are noteworthy - the entire region has been hit by this epidemic. And although it's important we not forget about this epidemic, there is much more to Appalachia than prescription drugs.

Although President Trump has often promised to bring jobs back to the coal industry in West Virginia and the rest of the region, that promise has remained largely unfulfilled. After a year in office nearly 1,000 coal jobs have returned to West Virginia but many other states like Ohio and Kentucky took big losses in the market amounting to an addition of just 745 jobs (Kahn, 2017). Coal is an industry that has long been struggling because of EPA regulatory guidelines and the sheer fact that coal is not clean and it's not cheap. The team of writers and editors at 100 Days in Appalachia is following its mission to disrupt those narratives and offer new perspectives from Appalachia, a region that is vastly underserved, misrepresented, and desperate for change.

\section{Introduction}

Appalachia is an area many don't hear about too often. Partly because they don't know how large the region really is and because it is consistently ill-defined. West Virginia is the only state completely inside the region of Appalachia, so it's often assumed West Virginia is Appalachia. But the region is much more diverse. It includes fracking in Pennsylvania, elections in Alabama and pig farms in Ohio. It is an area of the country that is starkly underserved. In result, professors and journalists at the West Virginia University Reed College of Media recognized a gap between Appalachia and the rest of the country and offered a solution. 100 Days in Appalachia is a digital 
publication designed to tell the stories of the region and help those unfamiliar with the region make sense of the deeply rooted culture and history of Appalachia. This publication has found a way to break through filter bubbles and tell stories that need to be told, which has created the ideal model for grassroots publications. This model will be used to create a blueprint guide to develop digital publications and give a voice to areas of the country who face similar challenges to Appalachia.

There are many variables that contribute to a publication: audience, funding, medium, writers, editors, topics, and functions. So where do you start? Most would say an idea and they'd be right. 100 Days in Appalachia has identified a part of the country that needs to tell its story and with big change in the White House, it was easy for them to decide where to start. Today's political and social climate isn't exactly media friendly, and really reaching an audience is becoming increasingly difficult. According to a 2016 Gallup poll, the nation's trust in media has fallen significantly over the past few years with "...32\% saying they have a great deal or fair amount of trust in the media". That number is down eight points from 2015 to 2016, but a lot has changed over the past year (Swift, 2016). Politicians, journalists and activists are fighting back against the rhetoric that has spread through the headlines about "fake news," false reports, and dirty journalism in spite of Trump's war on journalism. Although correlation does not always mean causation, a recent report found media confidence has gone from an alltime low of $32 \%$ to a near $48 \%$ just in the past year (Kahn, 2017).

Understanding what one is up against when one is part of the media is important because it's not a level playing field. The landscape is increasingly non-traditional and finding out what an audience wants or needs is the toughest part of the job. Anyone can publish a story but its impact depends on varying factors that many don't have or even know how to acquire. The media industry is extremely diverse and no publication is the same, no journalist is the same and no story is the same.

\section{Publication Building Toolkit Mission and Purpose}

Journalists all have the same mission. To gather facts and report the truth, or as defined by the Society of Professional Journalists, “...provide [this] information in an 
accurate, comprehensive, timely and understandable manner." And although our mission may align, our purpose varies (Society of Professional Journalists, 2014).

Think of it this way,

"Whereas you might achieve a goal or complete a strategy, you cannot fulfill a purpose; it's like a guiding star on the horizon-forever pursued but never reached. Yet although purpose itself does not change, it does inspire change. The very fact that purpose can never be fully realized means that an organization can never stop stimulating change and progress." - David Packard, 1960

In summary, Mission: what we do Purpose: why we do it

This begs the questions, what exactly is the mission of 100 Days in Appalachia and how do we define it? What is our purpose and how do we define it? It's important to constantly remind yourself why you're covering the stories you do and who you're covering them for. Post it in your newsroom and on the front page of your website so you and your audience don't forget why you're here.

The development of a mission and purpose is a crucial part to any publication. Your mission will serve as something your entire staff references to stay focused and achieve your ultimate goal. Although initially 100 Days in Appalachia was an attempt to navigate the Trump presidency through the eyes of Appalachia, it became much bigger than that when they realized people were paying attention (Friedman, 2014).

There is a lot of information in this toolkit. It's important to remember this is researched information brought to you by organizations who are either somewhat or highly developed. While all of the information is valid, following rules and guidelines may not work for everyone. It's more of a "keep this in mind" toolkit. In a recent article, executive director Dana Coester mentions the initial work that went into the idea behind 100 Days in Appalachia. But for them, everything changed the day after the 
2016 election, "...I wrote a one-paragraph thing and we launched. We could have just done this. It was infinitely easier to just start doing something instead of planning to do something" (Lichterman, 2018).

Planning everything out always seems like a sure thing at the beginning, but there could be a single factor that could change the entire trajectory of your publication. One might also consider how rapidly the landscape changes - journalism has no end game. Platforms, technology, content - and journalists themselves - will continue to find new ways to innovate and educate, and so should you.

If you think about it, only a few years ago AR/VR was something that very few had access too. Now, you can access it simply by downloading an app on your phone. Remember when you had to search the web to get your news? Now, everything you need to know is at your fingertips through a smartphone or other technology.

\section{Staff}

Building a team starts with identifying the needs of the publication. These are some positions that are typical to a newsroom:

Editor-in-Chief: I run the show.

General Manager: I work behind the scenes to make sure nothing goes wrong.

Digital Managing Editor: I control what it is and where it goes.

Copy Editor(s): We make sure the content brought to us by reporters and freelancers is polished and ready for the world.

Reporter(s): We cover everything, but stay in line with the mission of the publication.

Digital Content Producer: I create content specifically for the web. Multimedia Producer: I shoot photos and videos and turn them into distributable multimedia content. 
Web Developer: I make sure the website runs as efficient as possible and is easy to navigate for our audience.

Curation: I pull content and story ideas from our partners.

Social Media Producer: I transform content into something easily consumed on social platforms.

Freelancers: We have more freedom than reporters and take more risks.

While there are many jobs you can assign in your newsroom, often times you'll have one person doing multiple things. For example, 100 Days in Appalachia has a small editorial team who often develop their own content and a web developer who doubles as a videographer. They've invested in people with wide skill sets who can offer more than a quota. More importantly, they've added people to their team who have shared interests in the publication's mission. Building the right team isn't just about finding the right people though, it's also about creating an environment that people actually want to work in. A culture, if you will. Researchers at the Poynter Institute have identified some defining themes for a healthy newsroom culture (Clark, 2014):

- Where craft is tied to mission and purpose

- Where workers are learning all the time

- Where doors are opened rather than closed

- Where risk is rewarded

- Where coaching people is more important than fixing stories

- Where there is constant conversation

The quality of work that your publication produces is dependent on the environment your team works in. If your team doesn't feel like they're learning, or feel as though they're not valued - the publication will reflect that. 
Is journalism without diversity really journalism?

Diversity hasn't always been a key component of a successful newsroom. In fact, it's still a concept many organizations have yet to grasp.

In an annual survey conducted by the American Society of News Editors, researchers found that only 17 percent of minorities make up the modern day newsroom. A number that hasn't changed much over the past decade. Researchers also found that women make up one-third (39 percent) of newsrooms (American Society of News Editors, 2017).

\section{Why does this matter?}

Well, there are a lot of reasons why but the most important part of diversifying your newsroom is simple: to fairly represent the community around you. No matter where you live in the country, diversity exists. You can't tell stories with one voice or one point of view.

The American Press Institute emphasizes two key points in diversifying your newsroom:

Diversity is a business imperative.

"Concentrated efforts to highlight diversity are necessary for reaching new audiences and staying relevant to younger changing audiences. Readers pay attention to the content that speaks to or serves their identity" (American Press Institute)

The most important thing to remember here is to not get sucked into catering specifically to those audiences. You might get most of your views from women, but that doesn't mean you should start to publish more content for that specific audience.

Diversity is a journalism imperative. 
"Without accounting for the range of lived experiences, we fail to serve parts of our communities. Journalism, in its truest form, should be produced for the benefit of all, not only those who wield a particular power, class or authority."

Diversity is an element of education. Not just for your newsroom, but for your readers as well. The goal is to offer something different to your readers, disrupt typical narratives, and show your community that you're committed to getting it right.

100 Days in Appalachia is doing just that. In a recent article published by the Lenfest Institute, 100 Days in Appalachia editor-in-chief highlights the publications commitment to diversity, "Obviously we have a lot of readers in the region, but we work really hard to help those readers understand that we're trying to make sure that their stories and independent journalists in the region are talking to the rest of the world, so that the rest of the world isn't getting it wrong, like they often are" (Lichterman, 2018).

People were getting Appalachia wrong. And it wasn't too hard to see that. The region is vast and encompasses many different cultures, traditions and people. So when the only news making it to national headlines is about poverty and coal and opioids, the journalists in the area felt an obligation to change that.

\section{Medium}

At one time we were all required to choose a path. That path might have been print or radio or broadcast, and it's important to stick by your training - but the field has changed. It's integrated. With social media, video and new, exciting technology. Social media, videos and technology are important components to any publication but especially in today's digital age.

In 2016, the Pew Research Center conducted a study analyzing The Modern News Consumer and found that nearly three-quarters of Americans prefer to get their news on their mobile phone and that number is continuing to rise (Pew Research Center, 2016). While it is important to think mobile, it's important to remember not to think just mobile.

For example, NowThis is a news organization that gets practically all of its traffic on Facebook. It's fast journalism. They publish 30 to 90 second videos on everything from the White House to saving a puppy's life. And it's perfect for them because that's 
what their audience wants to see. Nearly 80 percent of the NowThis audience is below the age of 35 - the publication has developed a niche, which are otherwise known as 'millenials'. But this can also be seen as a problem.

Millenials are between the ages of 22-37 and are one of the largest groups of current news consumers, but they're not all of it. And to compensate for the diversity of your audience, you have to utilize multiple platforms to reach everyone. If you look at 100 Days in Appalachia's model, most of the major content is native to their site. And then they use Twitter, Facebook and Instagram to publish as well, but in different ways.

The answer to your question, publish anywhere you like. But understand the different ways each tool can be used. A lot of publications house everything on sites like WordPress, because the sites can be built from scratch and manipulated any way you want. Developing your site can be a lengthy task and some would recommend outsourcing that project to a professional.

\section{Site Development}

Developing your site can be challenging. Which is why most would recommend hiring someone with the skills to help you build it. But if the funds don't call for it, here is a list of plugins found native to the 100 Days in Appalachia website.

Don't be frightened. It's a very long list. But look at it as more of a suggestion and reminder that there are a lot of functions WordPress or the hosting site of your choice will not do on its own. Plugins allow you to customize your website the way you want it. If you want to auto-post from the site to Facebook, most sites won't allow you to do that if you don't tell it to.

\section{Plugins and widgets native to 100 Days in Appalachia's website}

Allow Multiple Accounts - allows multiple accounts to be created, registered, and updated having the same email address.

AMP: Add AMP support to your WordPress site. 
Ask: a plugin to easily embed Ask Forms and Ask Galleries in WordPress.

Blog2Social: Social Media Auto Post \& Scheduler: Auto publish, schedule and share posts on social media: Facebook, Twitter, Google+, XING, Linkedln, Instagram...can crosspost to pages and groups.

Cuckoo Plugin: A required plugin for the Cuckoo theme you purchased from ThemeForest. It includes a number of features that you can still use if you switch to another theme.

Custom Facebook Feed Pro Personal: Add a completely customizable Facebook feed to your WordPress site.

Disable Comments: Allows administrators to globally disable comments on their site. Comments can be disabled according to post type.

Duplicate Post: Clone pages and posts.

Facebook Instant Articles and Google AMP Pages by PageFrog: The PageFrog plugin allows you to easily publish and manage your content directly from WordPress for Facebook Instant Articles (FBIA) and Google Accelerated Mobile Pages (AMP) with full support for ads and analytics.

Insert Headers and Footers: Allows you to insert code or text in the header or footer of your WordPress blog.

Instant Articles for WP: Add support for Instant Articles for Facebook to your WordPress site.

Jetpack by WordPress.com: Bring the power of the WordPress cloud to your self-hosted WordPress. Jetpack enables you to connect your blog to a WordPress.com account to use the powerful features normally only available to WordPress.com users. 
JSON Basic Authentication: Basic authentication handler for the JSON APO, used for development and debugging purposes.

LiteSpeed Cache: WordPress plugin to connect to LSCache on LiteSpeed Web Server.

MailChimp for WordPress: MailChimp for WordPress by lbericode. Adds various highly effective sign-up methods to your site.

ManageWP - Worker: We help you efficiently manage all your WordPress websites from one place. Updates, backups, 1-click login, migrations, security and much more.

Mashshare Share Buttons: Mashshare is a share functionality inspired by the great website Mashable for Facebook and Twitter. More networks available.

Post Tracking: Plugin for tracking posts.

Post Types Order: Posts Order and Post Types Objects Order using a Drag and Drop Sortable javascript capability.

Publish to Apple News: Export and sync posts to Apple format.

Recent Posts Widget Extended: Enables advanced widget that gives you total control over the output of your site's most recent posts.

Repost plugin: Plugin for reposting WordPress posts.

Resize Image After Upload: Automatically resize uploaded images to within specified maximum width and height. Also has option to force recompression of JPEGs. Configuration options found under Settings > Resize Image Upload.

Scripts and Styles: Allows WordPress admin users the ability to add custom CSS and JavaScript directly to individual post, pages or custom post types. 
Smart Slider 3 Pro: The perfect all-in-one responsive slider solution for WordPress.

Social Icons Widget by WPZOOM: Social icons widget to displays links to social sharing websites. Supports more than 80 sites and includes 400 icons. Sort icons by drag and drop and change their color easily.

Theia Sticky Sidebar: Glues your website's sidebars, making them permanently visible while scrolling.

TinyMCA Advanced: Enables advanced features and plugins in TinyMCE, the visual editor in WordPress.

Visual Sidebar Editor: An add-on that allows you to use WPBakery Visual Composer or WordPress editor to override sidebars.

Wordable: This plugin helps you configure your blog for Wordable.

WordPress Popular Posts: A highly customizable widget that displays the most popular posts on your blog.

WP Add Custom CSS: Add custom CSS to the whole website and to specific posts, pages and custom post types.

WP Hide Post: Control visibility of items on your blog by making posts/pages hidden on some parts, while still visible in other parts and search engines.

WP Tiles: Add fully customizable dynamic tiles to your WordPress posts and pages.

WPBakery Visual Composer: Drag and drop page builder for WordPress. Take full control over your WordPress site, build any layout you can imagine - no programming knowledge required. 
Yoast SEO: The first true all-in-one SEO solution for WordPress, including on-page content analysis, XML sitemaps and much more.

\section{Content}

It's the big question: what are you going to cover? It's not everything, because everything means you're not bringing anything new to the table. There are many organizations out there that have figured out what they want to do and how to do it well.

If you've ever scrolled through your newsfeed, I'm sure you've come across the publication called Racked. Racked is owned by Vox Media - this also the organization that owns Vox, SBNation, The Verge and several other media outlets. If you know anything about Racked, you know it's a fashion based publication. They publish articles, but they also develop really amazing videos that connect with their audience.

Just like Racked, you'll be tasked with figuring out what your audience wants to see. That's the big dilemma right there: is it our job to guess what readers want or should they be telling us? The answer is both. There are tools all across the internet that allow publications to track user behavior, responses and pretty much anything else that has to do with the relationship between an audience and content. These tools are also known as analytics.

But in order to figure out what your audience wants, you kind of have to backtrack. Go into the development of your publication with an idea but don't be afraid to pivot. For example, 100 Days in Appalachia was not initially meant to exceed the 100 day mark. It's been $\mathbf{4 7 4}$ days - the team has actively tracked every day Donald Trump has spent in office.

\section{Social Media}

How to use Facebook for news

Facebook is a valuable tool for a lot of publications and journalists alike. But it's also muddied the waters a lot over the past several years, and especially more recently, as Facebook attempts to push its way into the "media".

It's a love versus hate relationship. As previously stated, Facebook is indeed a valuable tool. It allows you to connect with parts of an audience you may not reach 
otherwise. But it also causes a lot of problems for journalists. The Columbia Journalism Review published an article titled "Facebook is eating the world" in which it discusses the many downsides of social media in journalism.

"Our news ecosystem has changed more dramatically in the past five years than perhaps at any time in the past five hundred. We are seeing huge leaps in technical capability-virtual reality, live video, artificially intelligent news bots, instant messaging, and chat apps. We are seeing massive changes in control, and finance, putting the future of our publishing ecosystem into the hands of a few, who now control the destiny of many" (Bell, 2016).

How many people do you know that want all of their news to come directly from social media? Well, a lot more than you think. In fact, according to a report done by the Nieman Lab in 2016 nearly half of all U.S. adults admitted they got their news from Facebook (Lichterman, 2016).

Facebook filters content to readers based on patterns of the content they like and share, so often times it doesn't offer a balanced view and instead clouds newsfeeds with Buzzfeed articles and advertisements for items users didn't even know they wanted (Lichterman, 2016).

Professor Dana Coester at the West Virginia University's Reed College of Media had a chance to discuss her "unrequited love affair" with Facebook in front of the Knight Commission on Trust, Media and Democracy where she pleaded that, "Democracy needs journalism more than it needs Facebook. And Facebook needs journalism more than we need Facebook" (Coester, 2018).

Local media can sustain itself without Facebook but it can also navigate successfully through the clutter to utilize the tool until journalists can collectively come together and "lead in the local social space with more trust, reach and impact than Zuckerberg" as Coester put it.

The lesson is to use Facebook and other social platforms, but use them wisely. It's important to avoid housing content directly on social media and push traffic back to your website as often as possible. Give the real power back to publishers and 
journalists. The Washington Post suggest change for Facebook will only come from the top (Washington Post, 2015). And although Zuckerberg has suggested the company with make strides in the coming years to filter power back to the local arena, many journalists are not holding their breath (Lafrance, 2018).

\section{The downsides of Social Media}

Social media has become the lifeblood of news in the 21st century. There isn't a newsroom out there that doesn't use it because it is a great tool. But would you believe there's a right and a wrong way to do so? Some things to keep in mind when starting to develop your social presence:

\section{Don't be a pseudo-outlet:}

Social media users tailor their preferences on social media to align with preexisting views, opinions, political affiliation, etc. This concept is called a filter bubble. Humans are naturally drawn to people who share their views and this idea often times transfers over to our social media. It's especially true on Facebook. Users follow pages that will reinforce their existing views and with the way technology works today, Facebook can track user behavior and "suggest" posts or people with that same behavior.

\section{The master behind the pseudo-event:}

A pseudo-event is an event produced with the sole purpose of generating media attention and publicity (a common public relations tactic but affects news media nonetheless).

This is an idea reinforced by Daniel Boorstin in his novel "The Image: A Guide to pseudo-events in America." These are events that have been constructed strictly to draw media attention, or as Boorstin put it, "The celebration is held, photographs are taken, the occasion is widely reported" (Boorstin, 1962).

Give your audience something that will not only inform them, but make them think. News isn't covering a story for the sake of covering a story, your publication serves a purpose. 


\section{Beware of fake news:}

"Fake news" are false stories that appear to be news, which are spread on the internet using other media, usually created to influence political views or as a joke. In a study conducted in 2017, The Information Society Project at Yale Law School partnered with The Floyd Abrams Institute for Freedom of Expression to look deeper into the problems with fake news and potential solutions (Yale Law, 2017).

\section{The problems}

- Thanks to technology, anyone can create and disseminate "credible noise" as they called it

- Fake news "may be a byproduct of faster news cycles and increasing consumer demand for shorter-form content"

- Identification - how do we know what is and isn't true?

- Gatekeepers no longer have control over the market. Today's media climate doesn't give traditional news media the authority to decide what's real and what's not

- The switch from traditional content to digital content where popularity, engagement, and shares are favored over expertise and accuracy

\section{The solutions}

The solution itself lies with you and your audience. If you continue to nurture the relationship between you and your readers, you develop a loyal audience. And that's the first step. For starters, limit arguments supporting misinformation (New York Times, 2017). It's easy to post something you agree with but as a journalist, that's not your job.

Encourage your audience to scrutinize your content and anything else they read. Content is meant to be analyzed and questioned, which many news consumers still have trouble grasping. Your audience trusts that you're going to deliver factual, unbiased content but everyone makes mistakes. Allow yourself to grow with them. 
And finally, introduce new information. 100 Days in Appalachia whole mission is to do just that. They are taking everything the world thought it knew about Appalachia and hypothetically tossing it out the window.

\section{Audience}

What is an audience and who are they? These are two very simple questions but also two of the most important. Your audience is the basis for your entire publication, they are people. The ones who will read, like, share and repost the content that you publish (but remember, likes and shares shouldn't be the only focus). So when you're developing your ideas and thinking about moving forward, first think about who is going to be interested in what you're publishing. Because without an audience, content is simply that, content. It gets lost in space and its impact is minimal.

For a region like Appalachia, impact is the goal. For 100 Days in Appalachia, it's not just about telling stories, it's about reaching the people who need to hear them. And those people are the ones living outside of Appalachia. And they knew that was their target from the beginning. Specifically, 100 Days in Appalachia wants to, "...use its local knowledge and boots-on-the-ground approach to help readers outside the region have a more nuanced understanding of Appalachia while highlighting the area's diversity" (Lichterman, 2018).

It's not easy, as you'll soon find out. And they did too - not all of the feedback has been positive. But with the negatives come the positives. 100 Days in Appalachia has reached a lot of people and will continue to do so because they use their resources wisely. They have identified what audiences might or will respond most to their content and in turn have maximized their time and coverage and hope to gain the loyalty of that audience (Lichterman, 2018).

\section{How to maintain audience relationships}

Once you figure out who your audience is and it continues to grow, you'll have to constantly work to maintain that connection. Just because they stick around for a while, doesn't mean they always will. 
The real question ends up being, how do you maintain audience loyalty? We touched on loyalty a bit before, but it's important to drive this point home. Identifying people who want to read your content is key, but it's crucial that you nurture those relationships as well.

Which means, publishing content they'll actually want to read, tracking reading habits (analytics) so you know when they'll be more likely to read, understanding where they get their content from and of course, staying focused. It's easy to get distracted by hard, fast news. But the media market is already congested by 24 -hour news cycles and Facebook's constant attempt to undermine real, groundbreaking journalism (Friedman, 2014)

1. Publish content and lots of it. Your audience should have something fresh to look at every time they visit the site or it's social media pages.

2. Maintain your credibility. Which means stay focused and don't publish just for the sake of getting clicks. Distrust in media is already high enough.

3. Educate and adapt. In an article published by the Columbia Journalism Review, journalist Ann Friedman discusses James G. Websters' The Marketplace of Attention (Friedman, 2014). She summarizes several points about audience Webster makes throughout the book, "even if users do have some idea of what news and information they want (and it's not entirely clear they do), they don't know how or where to find it. And they might not have the time to figure it out." Help your audience understand not only what you're telling them, but where it's coming from. And recognize when you need to change your approach.

100 Days in Appalachia had to make some really big changes once they decided that this project was going to continue. The publication had already invested so much time and money into the development of this publication, "We'd built this brand, we'd built this audience, we'd built this platform and it made sense to keep it going," commented Jesse Wright, news director and 100 Days in Appalachia's partner with West Virginia Public Broadcasting (WVPB). It was an easy solution for them - just keep going (Lichterman, 2018). 


\section{Funding}

Funding can be a daunting task for publications. It's easy to say you want to do something, but you need the means to do it. In doing so, it's important you find organizations that want to be a part of your mission. But all of your money isn't going to come from partnerships. This is a battle 100 Days in Appalachia is facing right now. In a recent article published by the Lenfest Institute, editors dive into the numbers behind the publication (Lichterman, 2018). Be sure to keep in mind, the publication was initially only supposed to last 100 days so their initial funding was meant for just that.

With the realization that it wasn't going to be enough for the team to sustain itself after December 2018 - they had to figure out new ways to support their publication and its people.

\section{Partnerships}

Developing relationships with existing outlets is crucial for the success of your publication. It's a simple concept really - would it be easier for your publication to carry out its mission with the support of local news or to see them as the opposition? 100 Days in Appalachia has included many regional outlets such as the Ohio Valley Resource, the Daily Yonder and West Virginia Public Broadcasting in its mission.

\section{Grants}

A long and tedious process but rewarding if executed properly. Ask yourself a question: is your mission, your purpose something others can get on board with? Can you convince a board of people trained to recognize great ideas that you have a great idea? 100 Days in Appalachia was initially supported by grants from the Benedum Foundation and The Democracy Fund. And the good news is, they're not the only ones out there. Grants exists for local news and you can always propose something to an unlikely investor.

\section{Donations}

How do you think Wikipedia has survived all these years? Obviously, journalism and Wikipedia are not the least bit synonymous - but you get the point. 100 Days in Appalachia received a $\$ 15,000$ donation to support their efforts to get a correspondent on the ground in Washington, D.C. at all times. This wasn't trafficked through the 
website, but if you develop a loyal audience you could then turn that audience into "subscribers, members, or donors."

\section{Pay Wall}

This is something a lot of publications have implemented, small or large. The New York Times is the notable, unless you have a subscription, once you pass 5 articles you will continuously be prompted to commit to a monthly subscription. And it doesn't have to be substantial. Many locals news outlets charge around $\$ .99$ for their monthly subscription. Which seems like a small price to pay for the content you actually want to see.

\section{Restructuring}

Sometimes you can have a great idea that will just fall flat. And that's okay. One of the hardest things to grasp as a journalist is being able to just give up on a story. Because sometimes, it just doesn't go where you want it to go.

Restructuring can be costly, but ultimately it will only benefit you and your audience. A great example of restructuring would be a little local newspaper known as The Dominion Post. Based out of Morgantown, WV, this organization decided it was time for a change. Their website was outdated, the journalism weak and their efforts unclear. No one was paying attention. In just a few short months and with the help of some very knowledgeable people, they completely revamped their website and saw a tremendous increase in traffic to the site.

\section{Methodology}

The project was carried out in several steps to develop the media toolkit. This toolkit was designed using the model of 100 Days in Appalachia and resulted in a digital guide to provide insight on the possible development of similar independent publications.

\section{Analysis}

Step one will analyze 100 Days in Appalachia to better understand the mission, goals, and successes of the publication. As identified, 100 Days in Appalachia states its mission, in part, as the following: 
“Appalachia's stories are rich and complex. So are America's. When we tell them honestly, filter bubbles cannot contain them. We've assembled a team of editors and contributors who can help make sense of Appalachia for the world...because we call this region home. If you think you already know what we are going to say, we hope to surprise you."

The publication has identified an area in need of an outlet to tell its stories and has reached into communities throughout Appalachia to do just that. 100 Days in Appalachia has been active for just over a year and in that time has published nearly 350 stories, has a reach of 1.7 million on Facebook, and works nearly 40 journalists from across the country.

Step one included digging more deeply into social media statistics and analytics to discover the general successes of the publication. What data would be important for those that want to publish to understand, and how would they obtain that information.

It was also necessary to understand what components 100 Days in Appalachia found necessary in creating a successful publication and what the priorities are when doing so. When evaluating this process, it was understood that the landscape of local media and media itself is ever changing. 100 Days in Appalachia is constantly exploring new and innovative ways to tell stories and this will be continuously emphasized throughout the project.

To successfully gather this information, interviews were completed with several of the management and editorial team for 100 Days in Appalachia and analytics were pulled to access data and weigh statistical successes versus the information gathered from interviews.

It was important to note that interviews and additional research would be required to not only find what major components are necessary to develop a publication, but to discover what topics and/or verticals best serve the area of a publication.

\section{Compare}

After analyzing the mission, goals, and components of the 100 Days in Appalachia structure, it was important to compare it to other media outlets with similar 
models. Information was pulled from several media startups to get a well-rounded understanding of what it takes to develop a successful and functional publication.

An example of a similar publication is Berkleyside, a site developed completely for the area of Berkeley, California. Three editors and journalists from the area, Lance Knobel, Tracey Taylor and Frances Dinkelspiel founded the site in 2009. Similarly, the publication operates via WordPress, the same platform used by many online publications. But unlike 100 Days in Appalachia, Berkleyside gets most of its funding from advertisements, a typical model followed by independent publications that don't have access to university grants and funding or regional sponsorships.

Berkleyside co-founder Tracey Taylor offered several pieces of advice in an Adweek article, "do it your way, keep it lean and be transparent" (Raibano, 2011). This part of the project included further research into components other publications and media professionals like Tracey Taylor, found necessary to develop a successful media platform.

\section{Initial Toolkit Outline}

Following the analysis of the 100 Days in Appalachia publication and multiple other media outlets, a general framework was developed based off of gathered information and research. This framework is otherwise known as a toolkit and would ideally encompass a basic guideline for publication development.

- Mission and Audience

- What is the mission and central goal of the publication? Who do you want to reach?

- Local, regional or national audience

- What is the publications main focus? (Niche audience?)

- Platform

- Where do you want to publish? What is the best medium for your mission?

- Social, website...other?

- Analytics

- How will you publish on social? Facebook, Instagram, Twitter? 
- Analytics: What should you be looking at?

- Plugins: what tools will help a site run better/easier?

- Staffing

- Managing editors

- Contributing editors

- What are their roles?

- Payment?

- Freelancers or contracted reporters?

- Partnerships

- Who will you partner with, if at all?

- What type of partnership?

- Funding

- Grants

- Other sources: advertisements, sponsored content, affiliate links, regional sponsors, educational sponsors, etc.

- Content

- Writing

- How much long-form/short-form?

- Photos

- Wired services

- Freelancers

- Submitted photos

- Video

- How much long-form?

- How much short-form?

- Data Visualization and Infographics

- Will you hire someone to do this?

What are the obvious problems you can expect throughout this process? And what should be put in place in order to avoid them? 


\section{Bibliography}

American Press Institute. Diversity and inclusivity in journalism. Retrieved January 2018, from https://www.americanpressinstitute.org/diversity-programs/

American Society of News Editors. (2017). ASNE, Google News Lab release 2017 diversity survey results with interactive website. Retrieved January 2018, from https://www.asne.org/diversity-survey-2017

Bell, Emily. (7 March 2016). Facebook is eating the world. Retrieved December 2017, from https://www.cjr.org/analysis/facebook_and_media.php

Boorstin, Daniel. (1962). The image: a guide to pseudo-events in America. New York, New York: Harper \& Row.

Chokshi, Niraj. (18 September 2017). How to fight fake news. Retrieved November 2017, from https://www.nytimes.com/2017/09/18/business/media/fight-fakenews.html

Clark, Roy Peter. (2014, December 6). What defines a healthy newsroom culture? Retrieved December 10, 2017, from https://www.poynter.org/news/what-defineshealthy-newsroom-culture

Coester, Dana. (27 April 2018). We are not winning. Retrieved April 2018, from https://medium.com/trust-media-and-democracy/we-are-not-winning2fab9070b5c4

Dewey, Caitlin. (3 June 2015). If you use Facebook to get your news, please - for the love of democracy - read this first. Retrieved December 6 2017, from https://www.washingtonpost.com/news/the-intersect/wp/2015/06/03/if-you-use- 
facebook-to-get-your-news-please-for-the-love-of-democracy-read-thisfirst/?noredirect=on\&utm_term=.e85f9e9f8e57

Friedman, Anne. (September 2014). How to build an audience. Retrieved November 22, 2017, from https://www.cjr.org/innovations/how_to_build_an_audience.php

Hedegaard H, Warner M, Miniño AM. Drug overdose deaths in the United States, 19992016. Hyattsville, MD: National Center for Health Statistics. 2017/ CDC. Wideranging online data for epidemiologic research (WONDER). Atlanta, GA: CDC, National Center for Health Statistics; 2016. Available at http://wonder.cdc.gov

Kahn, C. (2017, October 3$)$. The press, branded the 'enemy' by Trump, increasingly trusted by the public. Retrieved December 18, 2017, from https://www.reuters.com/article/us-trump-effect-media-poll/the-press-brandedthe-enemy-by-trump-increasingly-trusted-by-the-public-reuters-ipsos-pollidUSKCN1C813L?feedType=RSS\&feedName=politicsNews\&utm_source=Twitte r\&utm_medium=Social

Shaffer, A. (2017, June 12). The "H" word: fighting negative language stereotypes in Appalachia. Retrieved December 21, 2017, from https://eberly.wvu.edu/newsevents/eberly-news/2017/06/12/the-h-word-fighting-negative-languagestereotypes-in-appalachia

Lafrance, Adrienne. (1 May 2018). Mark Zuckerberg doesn't understand journalism. Retrieved April 14 2018, from https://www.theatlantic.com/technology/archive/2018/05/mark-zuckerbergdoesnt-understand-journalism/559424/

Lichterman, Joseph. (26 May 2016). Nearly half of U.S. adults get news on Facebook, Pew says. Retrieved January 2018, from http://www.niemanlab.org/2016/05/pewreport-44-percent-of-u-s-adults-get-news-on-facebook/ 
Lichterman, Joseph. (2018, April 19). More than just a pop-up: How the collaborative newsroom 100 Days in Appalachia has grown. Retrieved April 2018, from https://www.lenfestinstitute.org/solution-set/2018/04/19/100-days-appalachiadonald-trump/

Park, A. (2017, January 24). The Story Behind the Viral Photo of an Opioid Overdose. Retrieved January 5, 2018, from http://time.com/4634809/photo-opioid-addiction/ Pew Research Center. (6 July 2016). Pathways to news. Retrieved December 2017, from http://www.journalism.org/2016/07/07/pathways-to-news/

Raibano, Lauren. (29 March 2011). How to start your own local news site: tips from a Berkleyside co-founder. Retrieved November 2017, from https://www.adweek.com/digital/how-to-start-your-own-local-news-site-tips-froma-berkeleyside-co-founder/3/

Society of Professional Journalists. (2014, September 6). SPJ Code of Ethics. Retrieved November 22, 2017, from https://www.spj.org/ethicscode.asp

Swift, A. (2016, September 14). Americans' Trust in Mass Media Sinks to New Low. Retrieved December 18, 2017, from http://news.gallup.com/poll/195542/americans-trust-mass-media-sinks-newlow.aspx?version=print

Yale Law. (March 2017). Fighting Fake News, Workshop Report. Retrieved December 2017, from https://law.yale.edu/system/files/area/center/isp/documents/fighting_fake_news__workshop_report.pdf 